\title{
Isotopic Effect on the Gel and Glass Formation of a Charged Colloidal Clay: Laponite
}

\author{
Flavio Augusto de Melo Marques, ${ }^{* \dagger}+$ Roberta Angelini, ${ }^{\ddagger} \S$ Giancarlo Ruocco, ${ }^{\prime \prime}$, and Barbara Ruzicka ${ }^{\ddagger}, \S$ \\ ${ }^{\dagger}$ Departamento de Física, Universidade Federal de Lavras, C.P. 3037, 37200-000 Lavras, MG, Brazil \\ ${ }^{\ddagger}$ ISC-CNR, Sede Sapienza, I-00185 Roma, Italy \\ ${ }^{\S}$ Dipartimento di Fisica, Sapienza Università di Roma, I-00185 Roma, Italy \\ "Center for Life Nano Science, IIT@Sapienza, Istituto Italiano di Tecnologia, Viale Regina Elena 291, 00161 Roma, Italy
}

ABSTRACT: The time evolution of both dynamic and static structure factors of a charged colloidal clay, Laponite, dispersed in both $\mathrm{H}_{2} \mathrm{O}$ and $\mathrm{D}_{2} \mathrm{O}$ solvents has been investigated through multiangle dynamic light scattering (DLS) and smallangle X-ray scattering (SAXS) as a function of weight concentration. The aging phenomenology and the formation of arrested states, both gel and glass, are preserved in $\mathrm{D}_{2} \mathrm{O}$, while the dynamics is slowed down with respect to water. These findings are important to understand the role played by the solvent in the interparticle interactions and for techniques such as neutron scattering and nuclear magnetic resonance that allow for the extension of the accessible scattering vectors and time scales.

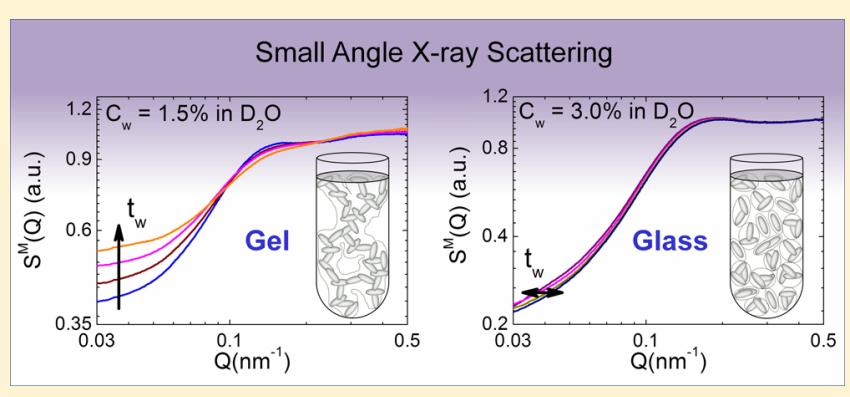

\section{INTRODUCTION}

A microscopic dynamics evolving with time is the signature of systems characterized by the aging phenomenon. Aging, dynamical arrest, and glass transition have been deeply studied through experiments, ${ }^{1-3}$ theory, ${ }^{4}$ and simulations ${ }^{5}$ over the past decade.

In this context colloidal clays have attracted considerable attention due to their characteristic aging behavior and rich phase diagrams. Depending on the ionic strength of the solvent and clay concentration they present liquid phases, gel and glassy states, as well as ordered nematic and columnar phases. $^{6-11}$

Among colloidal clays Laponite is a widely studied synthetic smectite clay that once dispersed in water forms a colloidal suspension used in many industrial and technological applications as a rheology modifier to products such as ceramics, paints, cosmetics, household cleaners, etc. ${ }^{12}$ It is characterized by a strong anisotropy due to the shape of the nanodisc particles and to the inhomogeneity of the charges (negative and positive, respectively, distributed on the faces and rims ${ }^{6}$ ) that originates a microscopic competition between directional attractive and repulsive interactions. These properties make Laponite an anisotropic particle, considered the future building blocks for novel self-assembled materials. ${ }^{13}$ The Laponite peculiar phase diagram has been largely investigated both experimentally, $14-22$ and theoretically ${ }^{23-30}$ in the last years. The system spontaneously evolves toward different arrested states depending on clay concentration and ionic strength. In particular in salt-free water conditions an equilibrium gel $^{31}$ and a Wigner glass ${ }^{32,33}$ can be recognized at weight clay concentrations $1.0 \% \leq C_{\mathrm{w}}<2.0 \%$ and $2.0 \% \leq C_{\mathrm{w}} \leq$
$3.0 \%$, respectively. Moreover at increasing waiting time a spontaneous glass-glass transition from a Wigner to a Disconnected House of Cards (DHOC) glass stabilized by attractive interactions has been recently found. ${ }^{34}$

The aging evolution of dynamical properties of Laponite has been broadly investigated through different scattering techniques. $^{34-41}$ In particular dynamic light scattering (DLS) has been widely exploited to probe the evolution of fast and slow relaxations as a function of waiting time $\left(t_{\mathrm{w}}\right)^{17,37,42-48}$ in aqueous Laponite suspensions. A recent DLS study of two samples at $1.5 \%$ and $3.0 \%$ weight concentrations in $\mathrm{H}_{2} \mathrm{O}, \mathrm{HDO}$, and $\mathrm{D}_{2} \mathrm{O}$ has been performed to investigate the effect of the $\mathrm{H} /$ $\mathrm{D}$ isotopic substitution in the solvent. ${ }^{49}$ However, an extended study at different concentrations and different length scales is missing as well as measurements on the structure of the system under $\mathrm{H} / \mathrm{D}$ isotopic substitution.

The most direct way to investigate how Laponite suspensions in $\mathrm{D}_{2} \mathrm{O}$ evolve from a liquid phase to an arrested state (gel and/ or glass) is to measure the evolution with time of both dynamic and static structure factors. Inspired by the pioneering work by Avery and Ramsay that studied dynamics and structure of Laponite suspensions ${ }^{50}$ we performed an extensive and systematic DLS and small-angle X-ray scattering (SAXS) study on samples in the concentration range $C_{\mathrm{w}}=(1.5-3.0)$ $\%$ at different length scales in both $\mathrm{H}_{2} \mathrm{O}$ and $\mathrm{D}_{2} \mathrm{O}$ solvents to understand the role played by $\mathrm{H} / \mathrm{D}$ isotopic substitution and how it affects the aging dynamics and the formation of arrested

Received: December 14, 2016

Revised: April 4, 2017

Published: April 4, 2017 
states. This study is also crucial for different experimental techniques which require isotopic substitution, such as nuclear magnetic resonance and neutron scattering, that allow for the exploration of larger scattering vectors and time scales. ${ }^{51}$

\section{MATERIALS AND METHODS}

Laponite is a synthetic layered silicate with chemical structure of the unitary cell constituted by six octahedral magnesium ions sandwiched between two layers of four tetrahedral silicon atom groups, obeying the empirical molecular formula $\mathrm{Na}^{+0.7}\left[\left(\mathrm{Si}_{8} \mathrm{Mg}_{5.5} \mathrm{Li}_{0.3}\right) \mathrm{O}_{20}(\mathrm{OH})_{4}\right]^{-0.7 .52}$ The unitary cell is repeated around 1500 times in two dimensions to form each Laponite disc with a diameter of $25 \mathrm{~nm}$ and a thickness of 1 $\mathrm{nm} .{ }^{6}$ The substitution of magnesium ions by lithium ions in the octahedral sheet originates a negative charge of $-0.7 e$ in a unit cell. These elementary charges are uniformly distributed over the surface of Laponite discs, and therefore the dissociation of $\mathrm{OH}^{-}$ions from the rims raises the $\mathrm{pH}$ of the solution and leads to their positive charge. ${ }^{53}$ Thus, the suspension is composed by nanosized discs with inhomogeneous charge distribution: negative on the surface, around several hundred unit charge $e$, and positive on the rims, ten times lower for a salt-free system, as in our case. ${ }^{20,35,53}$

The samples were prepared, following the detailed protocol described in ref 6: The oven-dried Laponite $\mathrm{RD}$ manufactured by Laporte Ltd. was dispersed under stirring for $30 \mathrm{~min}$ both in ultrapure deionized water $\left(\mathrm{H}_{2} \mathrm{O}\right)$ and deuterium oxide $\left(\mathrm{D}_{2} \mathrm{O}\right)$ with purity $\geq 99.9 \%$ produced by EURISO-TOP. Soon after stirring, the system was filtered through a $0.45 \mu \mathrm{m}$ pore size Millipore filter. The origin of the waiting time $\left(t_{\mathrm{w}}=0\right)$ is the time at which the suspension is filtered and sealed in glass tubes with $10 \mathrm{~mm}$ of diameter for DLS and in capillaries with $2 \mathrm{~mm}$ of diameter for SAXS measurements. The whole procedure has been carried out in a glovebox under $\mathrm{N}_{2}$ flux to prevent $\mathrm{CO}_{2}$ contamination. Samples at different weight concentrations in the range $1.5 \%$ to $3.0 \%$ in $\mathrm{H}_{2} \mathrm{O}$ and $\mathrm{D}_{2} \mathrm{O}$ were prepared with the same molar ratio; therefore, the weight concentration, $C_{w}$, reported in the text always refers to the case of $\mathrm{H}_{2} \mathrm{O}$.

Methods. DLS measurements were performed with a fiveangle setup. A solid-state laser with wavelength $\lambda=642 \mathrm{~nm}$ and power of $100 \mathrm{~mW}$ is focused in the center of a cylindrical cuvette. Single-mode fibers collect the scattered light at five different scattering angles at around $\theta=30^{\circ}, 50^{\circ}, 70^{\circ}, 90^{\circ}$, and $110^{\circ}$, which correspond to five different scattering vectors, according to the relation $Q=(4 \pi n / \lambda) \sin (\theta / 2)$, where $n$ is the refractive index of the solvent $\left(n_{\mathrm{D} 2 \mathrm{O}} \approx 1.326\right.$ and $n_{\mathrm{H} 2 \mathrm{O}} \approx 1.331$ for $\mathrm{D}_{2} \mathrm{O}$ and $\mathrm{H}_{2} \mathrm{O}$, respectively, at $\lambda \approx 642 \mathrm{~nm}$ and $T=25$ ${ }^{\circ} \mathrm{C}^{54}$ ). Time autocorrelation functions are then simultaneously computed at $Q=6.2 \times 10^{-4}, 1.1 \times 10^{-3}, 1.5 \times 10^{-3}, 1.8 \times 10^{-3}$, and $2.1 \times 10^{-3} \AA^{-1}$ by calculating the intensity autocorrelation function in the time range $10^{-6}-1 \mathrm{~s}$ as

$$
g_{2}(Q, t)=\frac{\langle I(Q, 0) I(Q, t)\rangle_{t}}{\langle I(Q, 0)\rangle_{t}^{2}}
$$

where $t$ is the delay time and $\langle\cdots\rangle_{t}$ denotes the time average. This technique permits us to explore both fast and slow relaxations in Laponite suspensions.

SAXS experiments were performed at the high brilliance beamline ID02 of the European Synchrotron Radiation Facility (ESRF) in Grenoble, France, to probe length scales from nanometers to microns and to obtain structural information for soft matter and related systems. The measured structure factors $\left(S^{\mathrm{M}}(Q)\right)$ have been obtained as described in ref 38 .

\section{RESULTS AND DISCUSSIONS}

DLS measurements were performed on Laponite suspensions at weight clay concentrations ranging from $1.5 \%$ to $3.0 \%$ in both ultrapure deionized and deuterated water.

Figure 1 shows the normalized intensity autocorrelation functions as obtained through DLS for samples at increasing

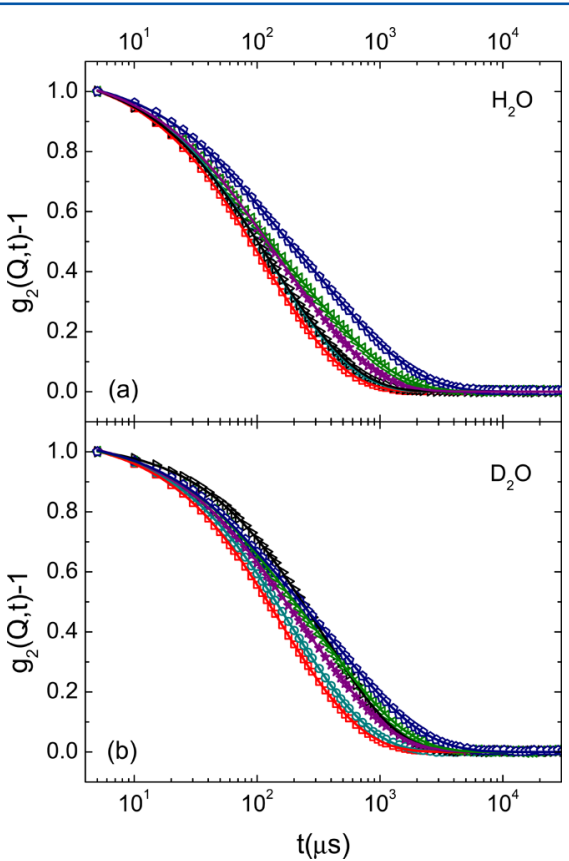

Figure 1. Semilog plot of normalized intensity autocorrelation functions as obtained through DLS at $Q=1.8 \times 10^{-3} \AA^{-1}$ for samples with increasing clay concentration in (a) $\mathrm{H}_{2} \mathrm{O}$ and (b) $\mathrm{D}_{2} \mathrm{O}$ solvents at initial waiting time $t_{\mathrm{w}}=7 \mathrm{~min}$. Clay concentrations are $\square=$ $3.0 \%, \triangleleft=2.8 \%$, $=2.5 \%, \triangleright=2.0 \%, O=1.8 \%$, and $\square=1.5 \%$. Full lines superimposed to symbols are fits obtained through eq 2.

weight concentrations in (a) $\mathrm{H}_{2} \mathrm{O}$ and (b) $\mathrm{D}_{2} \mathrm{O}$ solvents at initial waiting time $t_{\mathrm{w}}=7 \mathrm{~min}$. By increasing concentration the correlation curves slow down and become slightly more stretched.

The aging behavior and the time at which the sample reaches the arrested state strongly depend on $\mathrm{H} / \mathrm{D}$ isotopic substitution in the solvent and on clay concentration, as low concentrated samples take much more time to evolve with respect to high concentrated ones.

To better investigate this dependence we fit all correlation curves with a typical double exponential decay according to the expression $^{44}$

$$
g_{2}(Q, t)-1=b\left[a e^{-t / \tau_{1}}+(1-a) e^{-\left(t / \tau_{2}\right)^{\beta}}\right]^{2}
$$

where $b$ represents the coherence factor; $\tau_{1}$ is the microscopic or fast relaxation time associated with the interactions between a particle and the cage of its nearest neighbors; $\tau_{2}$ is the structural or slow relaxation time related to the structural rearrangement of particles; $\beta$ is a measure of its distribution width; and $a$ and $(1-a)$ are the amplitudes of the fast and slow relaxations, respectively.

Coherence factors $(b)$ obtained for all correlation functions are slightly dependent on $t_{\mathrm{w}}$, and their mean values are $0.847 \pm$ 
$0.005,0.897 \pm 0.003,0.917 \pm 0.007,0.911 \pm 0.011$, and 0.946 \pm 0.025 , respectively, for $Q=2.1 \times 10^{-3}, 1.8 \times 10^{-3}, 1.5 \times$ $10^{-3}, 1.1 \times 10^{-3}$, and $6.2 \times 10^{-4} \AA^{-1}$.

As shown in Figure 2 the fast relaxation time $\tau_{1}$ slightly increases (less than 1 order of magnitude) with increasing

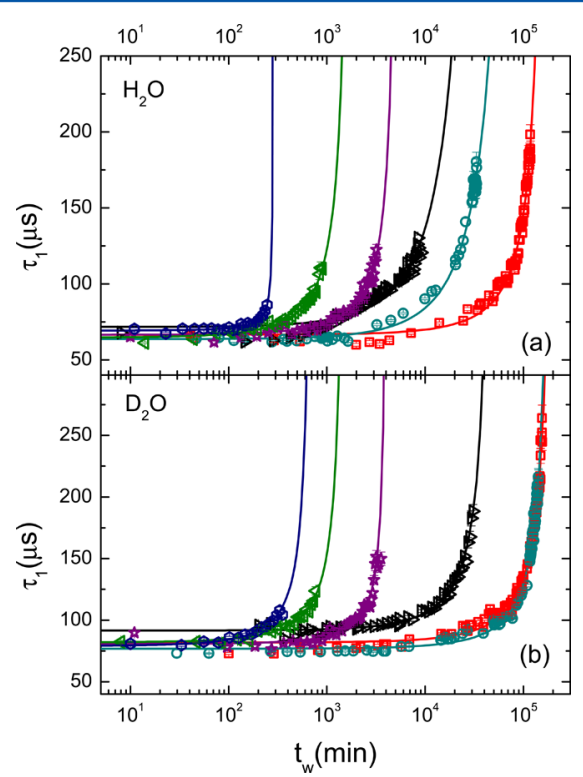

Figure 2. Semilog plot of the microscopic relaxation time $\tau_{1}$ as a function of waiting time for samples with increasing clay concentration in (a) $\mathrm{H}_{2} \mathrm{O}$ and (b) $\mathrm{D}_{2} \mathrm{O}$ solvents at $Q=1.8 \times 10^{-3} \AA^{-1}$. Clay concentrations are $\bigcirc=3.0 \%, \neg=2.8 \%$, 许 $=2.5 \%, \nabla=2.0 \%, O=$ $1.8 \%$, and $\square=1.5 \%$. Full lines superimposed to symbols are fits obtained through the expression $\tau_{1}=\tau_{1 \_0} \exp \left(B_{1} /\left(1-t_{\mathrm{w}} / t_{\mathrm{w}}^{\infty}\right)\right)$ where $\tau_{10}, B_{1}$, and $t_{\mathrm{w}}^{\infty}$ are fitting parameters.

waiting time depending on clay concentration and solvent: it departs from similar values for all concentrations $\left(\tau_{1} \approx 65 \mu \mathrm{s}\right.$ for (a) $\mathrm{H}_{2} \mathrm{O}$ and $\tau_{1} \approx 80 \mu$ s for (b) $\mathrm{D}_{2} \mathrm{O}$ ) and reaches higher values for low concentrated samples. At short waiting times the translational diffusion coefficient obtained by polarized DLS depends on the fast relaxation time $\tau_{1}$ and scattering vector $Q$ according to $D_{t}=1 /\left(\tau_{1} Q^{2}\right)$ and is also proportional to the viscosity $(\eta)$ through the Stokes-Einstein relation $D_{t}=K_{\mathrm{B}} T /$ $\left(6 \pi \eta R_{\mathrm{H}}\right)$, where $K_{\mathrm{B}}$ is the Boltzmann constant, $T$ the temperature, and $R_{\mathrm{H}}$ the hydrodynamic radius of the discshaped particle. This implies that $\tau_{1 \mathrm{Lapo}-\mathrm{D} 2 \mathrm{O}} / \tau_{1 \mathrm{Lapo}-\mathrm{H} 2 \mathrm{O}}=\eta_{\mathrm{D} 2 \mathrm{O}} /$ $\eta_{\mathrm{H} 2 \mathrm{O}}=1.23$ where $\eta_{\mathrm{D} 2 \mathrm{O}}=1.095 \mathrm{mPas}$ and $\eta_{\mathrm{H} 2 \mathrm{O}}=0.891 \mathrm{mPas}$ at $T=25{ }^{\circ} \mathrm{C} .{ }^{55}$ This indicates that the difference in the diffusion process at initial waiting times is mainly due to the difference in the solvent viscosity.

On the other hand, the slow relaxation time $\tau_{2}$ increases significantly with waiting time. This behavior can be attributed to a cage-diffusion process, where at short times the particles can escape from "cages" formed by neighboring particles, while at long times they cannot escape anymore and the system becomes arrested.

The $Q$ dependence of both the microscopic and structural relaxation times is reported in Figure 3 at all the investigated clay concentrations for (a) $\mathrm{H}_{2} \mathrm{O}$ and (b) $\mathrm{D}_{2} \mathrm{O}$ solvents at initial waiting time $t_{\mathrm{w}}=7 \mathrm{~min}$ together with a power law fit (solid lines) of the data as $\sim Q^{-n}$ with $n \approx 2$ indicating a diffusive dynamics at short waiting times. The same behavior has been found for all waiting times (of the order of months) following the dynamics of a low concentrated sample $C_{w}=1.5 \%$ as

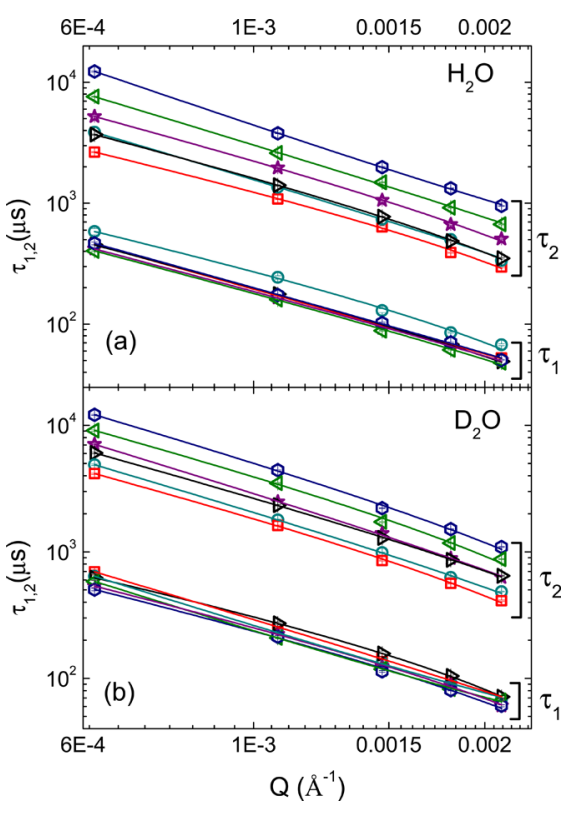

Figure 3. $\log -\log$ plot of the $\mathrm{Q}$ dependence of microscopic $\tau_{1}$ and structural $\tau_{2}$ relaxation times at initial waiting time $t_{\mathrm{w}}=7 \mathrm{~min}$ in (a) $\mathrm{H}_{2} \mathrm{O}$ and (b) $\mathrm{D}_{2} \mathrm{O}$ solvents for different clay concentrations: $\mathrm{O}=$ $3.0 \%, \triangleleft=2.8 \%$, is $=2.5 \%, \nabla=2.0 \%, O=1.8 \%$, and $\square=1.5 \%$. Solid lines are power law fits of the data as $\sim Q^{-n}$ where in the case of $\tau_{1}$ the mean values are $n=1.68 \pm 0.05\left(\mathrm{H}_{2} \mathrm{O}\right)$ and $n=1.67 \pm 0.04\left(\mathrm{D}_{2} \mathrm{O}\right)$ and in the case of $\tau_{2}$ are $n=2.17 \pm 0.27\left(\mathrm{H}_{2} \mathrm{O}\right)$ and $n=2.07 \pm 0.15$ $\left(\mathrm{D}_{2} \mathrm{O}\right)$.

reported in Figure 4 for (a) $\mathrm{H}_{2} \mathrm{O}$ and (b) $\mathrm{D}_{2} \mathrm{O}$ solvents. These findings are in agreement with previous studies on Laponite water $^{32,37,56,57}$ and heavy water suspensions ${ }^{41}$ performed only for the high concentration $C_{\mathrm{w}}=3.0 \%$.

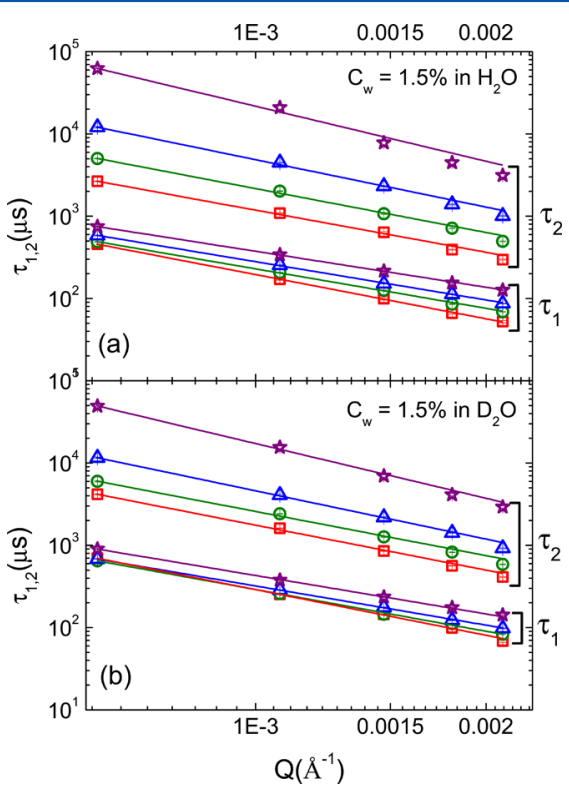

Figure 4. $\log -\log$ plot of the $Q$ dependence of microscopic $\tau_{1}$ and structural $\tau_{2}$ relaxation times for clay concentration $C_{\mathrm{w}}=1.5 \%$ in (a) $\mathrm{H}_{2} \mathrm{O}$ and (b) $\mathrm{D}_{2} \mathrm{O}$ solvents at increasing waiting times: $\square=42 \mathrm{~min}, \mathrm{O}$ $=34020 \mathrm{~min}, \triangle=74460 \mathrm{~min}$, and $\dot{\tau}=104760 \mathrm{~min}$ for $\mathrm{H}_{2} \mathrm{O}$ and $\square$ $=120 \mathrm{~min}, O=46080 \mathrm{~min}, \triangle=90720 \mathrm{~min}$, and $\mathrm{i}=129600 \mathrm{~min}$ for $\mathrm{D}_{2} \mathrm{O}$. Solid lines are power law fits of the data as $\sim Q^{-n}$. 
During the fluid to arrested state transition, the stretching parameter $\beta$, in agreement with findings in other clays, ${ }^{46}$ lowers from $\sim 0.8$ to $\sim 0.2$ as shown in Figure 5 for (a) $\mathrm{H}_{2} \mathrm{O}$ and (b) $\mathrm{D}_{2} \mathrm{O}$ solvents. It decays faster by increasing clay concentration.

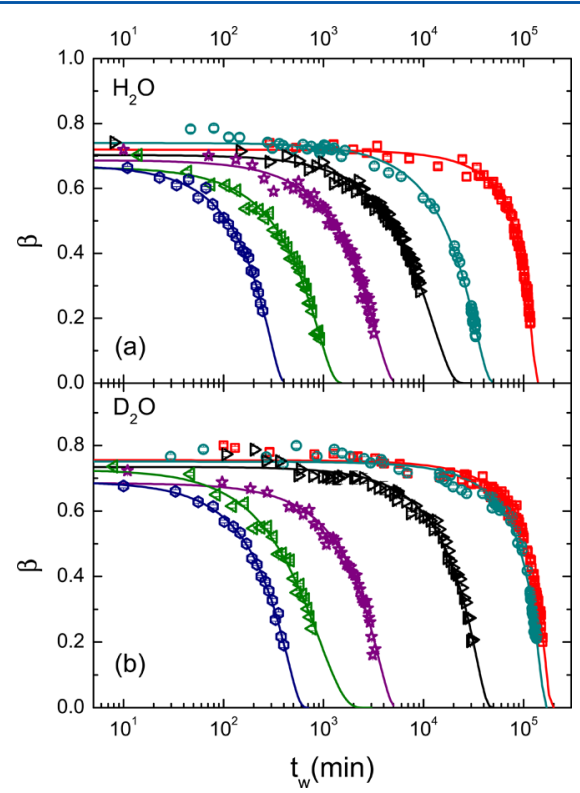

Figure 5. Semilog plot of the stretching parameter $\beta$ as a function of waiting time for samples with increasing clay concentration in $(a) \mathrm{H}_{2} \mathrm{O}$ and (b) $\mathrm{D}_{2} \mathrm{O}$ solvents at $Q=1.8 \times 10^{-3} \AA^{-1}$. Clay concentrations are $\bigcirc=3.0 \%, \triangleleft=2.8 \%$, 访 $=2.5 \%, \triangleright=2.0 \%, \bigcirc=1.8 \%$, and $\square=1.5 \%$. Full lines superimposed to symbols are fits obtained through the expression $\beta=\beta_{0} \exp \left(B_{\beta} /\left(1-t_{\mathrm{w}} / t_{\mathrm{w}}^{\infty}\right)\right)$ where $\beta_{0}, B_{\beta}$, and $t_{\mathrm{w}}^{\infty}$ are fitting parameters.

The slow relaxation time is well described by the two parameters $\tau_{2}$ and $\beta$ or by the mean relaxation time defined as ${ }^{44}$

$$
\tau_{\mathrm{m}}=\frac{\tau_{2}}{\beta} \Gamma\left(\frac{1}{\beta}\right)
$$

where $\Gamma$ is the Euler gamma function. The waiting time dependence of $\tau_{\mathrm{m}}$ for samples with increasing Laponite concentration is reported in Figure 6 for both (a) $\mathrm{H}_{2} \mathrm{O}$ and (b) $\mathrm{D}_{2} \mathrm{O}$ solvents. Previous studies have shown that it has a characteristic exponential growth reflecting the progressive slowing down of the dynamics according to the expression ${ }^{17,44}$

$$
\tau_{\mathrm{m}}=\tau_{0} \exp \left(\frac{B}{1-\left(t_{\mathrm{w}} / t_{\mathrm{w}}^{\infty}\right)}\right)
$$

where $\tau_{0}, B$, and $t_{\mathrm{w}}^{\infty}$ are fitting parameters and $t_{\mathrm{w}}^{\infty}$ represents the divergence of $\tau_{\mathrm{m}}$ associated with the formation of an arrested state: at the beginning the sample behaves like a liquid, and then with time the viscosity strongly increases up to reach an arrested state where the sample does not flow anymore if turned upside down. Figure 6(a) and (b) clearly shows that the mean relaxation time is strongly dependent on both clay concentration and isotopic substitution in the solvent. Fits of microscopic relaxation time and stretching parameter provide similar values of $t_{\mathrm{w}}^{\infty}$.

Figure 7 shows the divergence waiting times as a function of Laponite concentration in both $\mathrm{H}_{2} \mathrm{O}$ and $\mathrm{D}_{2} \mathrm{O}$ solvents. In agreement with previous studies in $\mathrm{H}_{2} \mathrm{O}$ the time needed to reach an arrested state decreases for increasing clay

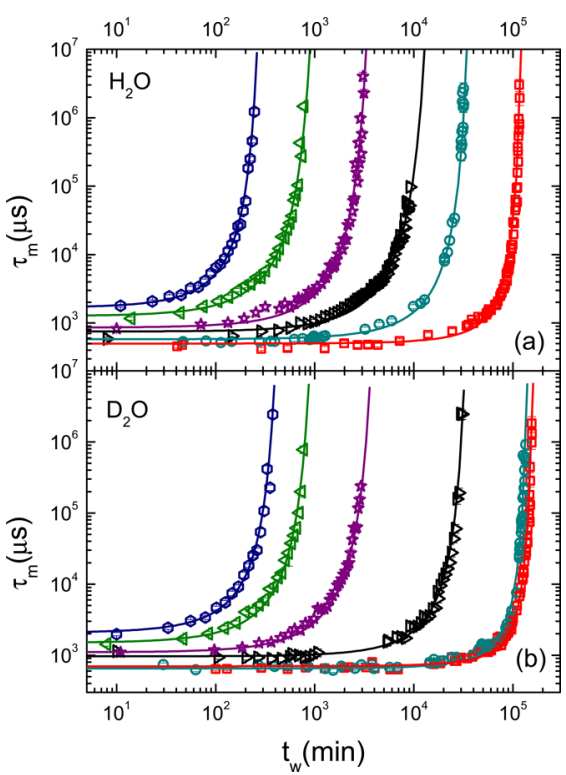

Figure 6. $\log -\log$ plot of the waiting time dependence of mean relaxation time $\tau_{\mathrm{m}}$ for different clay concentrations in (a) $\mathrm{H}_{2} \mathrm{O}$ and (b) $\mathrm{D}_{2} \mathrm{O}$ solvents at $Q=1.8 \times 10^{-3} \AA^{-1}$. Clay concentrations are $\mathrm{O}=$ $3.0 \%, \measuredangle=2.8 \%$, $\downarrow=2.5 \%, \nabla=2.0 \%, \bigcirc=1.8 \%$, and $\square=1.5 \%$. Solid lines represent fits obtained through eq 4.

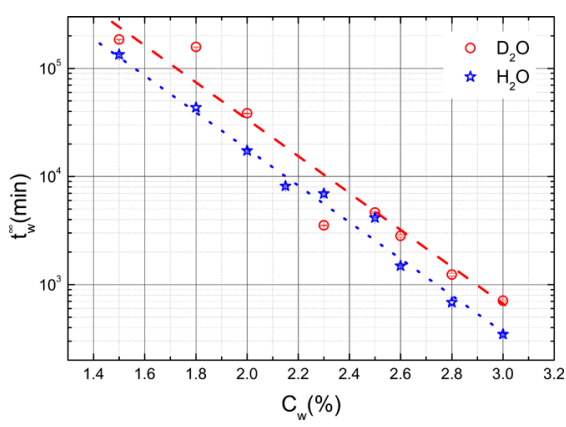

Figure 7. Semilog plot of the divergent waiting time $t_{\mathrm{w}}^{\infty}$ as a function of Laponite concentration for both $\mathrm{H}_{2} \mathrm{O}$ and $\mathrm{D}_{2} \mathrm{O}$ solvents at $Q=1.8 \times$ $10^{-3} \AA^{-1}$. Dotted and dashed lines are guides to the eye.

concentration $^{44}$ in both solvents, indicating that more concentrated samples arrest faster. Furthermore, at fixed clay concentration a considerable difference in the aging velocities is found for the two solvents: a slower aging behavior is obtained for most of the samples prepared in $\mathrm{D}_{2} \mathrm{O}$ with respect to $\mathrm{H}_{2} \mathrm{O}$. It cannot be due to the screening lengths of the two solvents since their relative permittivities are very similar $\left(\epsilon_{\mathrm{D}_{2} \mathrm{O}}=78.39\right.$ and $\epsilon_{\mathrm{H}_{2} \mathrm{O}}=78.06$ at $\left.T=25^{\circ} \mathrm{C}^{58}\right)$. Moreover the difference in solvent density is small $\left(1.1 \mathrm{~g} / \mathrm{cm}^{3}\right.$ for $\mathrm{D}_{2} \mathrm{O}$ compared with 0.99 $\mathrm{g} / \mathrm{cm}^{3}$ for $\mathrm{H}_{2} \mathrm{O}$ at $\left.\mathrm{T}=25^{\circ} \mathrm{C}^{59,60}\right)$, and Laponite density is 2.53 $\mathrm{g} / \mathrm{cm}^{3}$; therefore, the slight difference in buoyancy for such tiny discs will not significantly affect the aging of the sample. Furthermore, the values of $\mathrm{pH}=6.99$ and $\mathrm{pD}=7.43^{61}$ will guarantee the stability of the platelets since dissolution is not present in the range of $\mathrm{pH}$ between 3 and 10 for samples prepared and sealed in $\mathrm{N}_{2}$ atmosphere, ${ }^{62-64}$ and their small difference will not significantly affect the net charge on the discs. Therefore, we believe that the difference in the aging velocities for the two solvents could be related to the change in viscosity. Figure 7 provides also a clear mapping of the time needed to reach an arrested state at defined clay concentration 
and solvent and enables one to choose and prepare samples with an established arresting time.

The $B$ parameter that measures how fast $\tau_{\mathrm{m}}$ approaches the divergence is shown in Figure 8 as a function of $C_{w}$, and despite

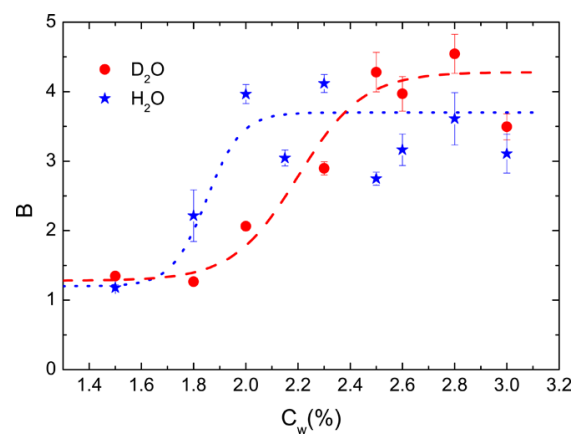

Figure 8. $B$ parameter as a function of Laponite concentration for both $\mathrm{H}_{2} \mathrm{O}$ and $\mathrm{D}_{2} \mathrm{O}$ solvents at $Q=1.8 \times 10^{-3} \AA^{-1}$. Dotted and dashed lines are guides to the eye.

fluctuations, it clearly presents a discontinuity (step behavior) for both solvents $\mathrm{H}_{2} \mathrm{O}$ and $\mathrm{D}_{2} \mathrm{O}$. Previous studies in water ${ }^{44}$ have reported the same discontinuity between two different constant values for low and high clay concentrations, indicating a transition between different arrested states. Recent studies have then clarified this scenario, showing that Laponite in $\mathrm{H}_{2} \mathrm{O}$ forms an equilibrium gel for $1.0 \%<C_{\mathrm{w}}<2.0 \%$ and a Wigner glass for $2.0 \% \leq C_{\mathrm{w}}<3.0 \% .^{31,33}$ The presence of this transition also in $\mathrm{D}_{2} \mathrm{O}$ indicates the existence of two different final arrested states for low and high clay concentrations. Moreover in the case of $\mathrm{D}_{2} \mathrm{O}$ the slight shift of the discontinuity toward higher values suggests that the formation of the high concentration state happens to higher clay concentrations.

To have information on the structure of low $\left(C_{w}=1.5 \%\right)$ and high $\left(C_{w}=3.0 \%\right)$ concentrated samples in $\mathrm{D}_{2} \mathrm{O}$, the waiting time dependence of the static structure factor has been followed through SAXS measurements as reported in Figure 9(a) and (b), respectively. At initial waiting times (dashed lines, dashed

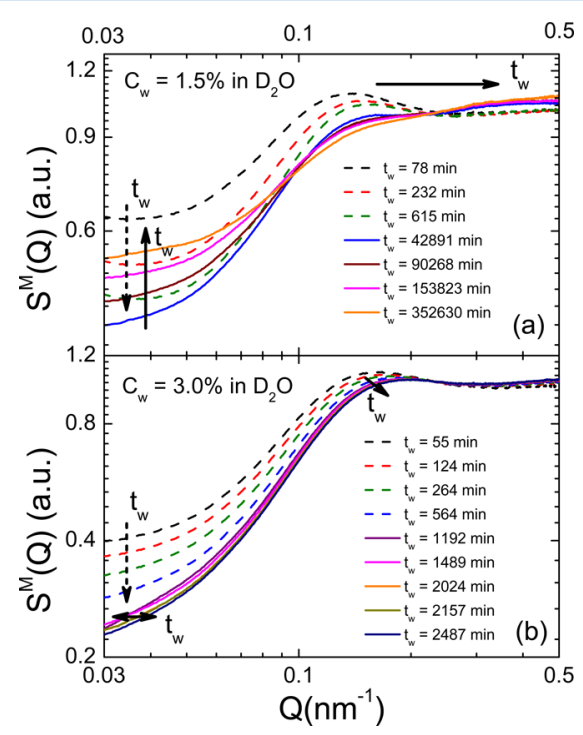

Figure 9. Measured static structure factor $S^{\mathrm{M}}(Q)$ as obtained by SAXS for samples at (a) low $C_{\mathrm{w}}=1.5 \%$ and (b) high $C_{\mathrm{w}}=3.0 \%$ Laponite concentration in $\mathrm{D}_{2} \mathrm{O}$ at different waiting times. $t_{\mathrm{w}}$ arrows), both low and high concentrated samples show a decreasing of intensity at low $Q$-values, probably due to surface processes of the particles taking time to reach a local equilibrium state before the aging phenomenon starts ${ }^{65}$ or to delamination of Laponite particles at early times. ${ }^{48}$ For longer waiting times (full lines, full line $t_{\mathrm{w}}$ arrows), as samples evolve and reach an arrested state, the static structure factor has significant different behaviors for the two concentrations. In particular while for the high concentrated sample the $S^{\mathrm{M}}(Q)$ shows only a slight decrease at low $Q$ and a small shift of the main peak toward higher $Q$ values (Figure 9(b)), low concentrated samples (Figure 9(a)) show a dramatic change. In this case a progressive increase of scattering intensity at low $Q$ and a significant shift of the main peak toward higher $Q$ values are observed. These behaviors are similar to those found in $\mathrm{H}_{2} \mathrm{O}$ solvent ${ }^{38}$ and indicate that the two samples reach two different final arrested states following different routes. ${ }^{44}$

In order to understand the nature of these two distinct arrested states we consider that the static structure factor of a gel is generally described by an excess scattering intensity at low $Q$ which reflects the correlation of the concentration fluctuations associated with the network structure and consequently indicates the formation of an inhomogeneous state; therefore Figure 9(a) denotes the formation of a gel structure. ${ }^{15}$ On the other hand the static structure factor of a glass is characterized by an almost constant intensity at low $Q$ that corresponds to the formation of a homogeneous state, ${ }^{15}$ as the one found in $S^{\mathrm{M}}(Q)$ for high concentrated samples (Figure 9 (b)). In addition, the position of the main peak, when the arrested state is reached (long waiting times), for the high and low concentrated samples is located, respectively, at $Q \approx 0.16$ $\mathrm{nm}^{-1}$ and $Q \approx 0.4 \mathrm{~nm}^{-1}$, corresponding to length scales of $\approx 40$ $\mathrm{nm}$ for high and $\approx 15 \mathrm{~nm}$ for low clay concentrations. Considering that the Laponite diameter is $25 \mathrm{~nm}$, this indicates that particles are mainly disconnected at high $C_{\mathrm{w}}$ (glass state) and probably bonded in a T-configuration at lower $C_{\mathrm{w}}$ (gel state). These findings demonstrate that also in the case of $\mathrm{D}_{2} \mathrm{O}$ solutions the picture of a gel at low concentrations and a glass at high concentrations is preserved.

The static structure factors in the gel $\left(C_{\mathrm{w}}=1.5 \%\right.$ Figure $10(\mathrm{a}))$ and in the glass state $\left(C_{\mathrm{w}}=3.0 \%\right.$ Figure $\left.10(\mathrm{~b})\right)$ in both solvents have been compared at short (full lines) and long (dashed lines) waiting times. It is evident that for both concentrations $S^{\mathrm{M}}(Q)$ does not vary remarkably by $\mathrm{H} / \mathrm{D}$ isotopic substitution, suggesting that the interaction potentials describing water Laponite suspensions apply also to the case of heavy water solvent.

\section{CONCLUSIONS}

In this work we have performed an extensive study on the aging behavior of Laponite suspensions in both $\mathrm{D}_{2} \mathrm{O}$ and $\mathrm{H}_{2} \mathrm{O}$ solvents at increasing clay concentration from $1.5 \%$ to $3.0 \%$. We found that the aging phenomenology and arresting mechanisms are preserved and that $H / D$ isotopic substitution affects the dynamics and leads to a slowing down of the aging. A clear mapping of the time needed to reach an arrested state at defined clay concentration and to also choose and prepare samples with established arresting time is obtained. Moreover, measurements of the static structure factors indicate that $\mathrm{H} / \mathrm{D}$ isotopic substitution does not affect the structure and that the arrested states reached at low $\left(C_{\mathrm{w}}=1.5 \%\right)$ and high $\left(C_{\mathrm{w}}=\right.$ $3.0 \%)$ concentrations in $\mathrm{D}_{2} \mathrm{O}$ are, respectively, gel and glass as in $\mathrm{H}_{2} \mathrm{O}$. 


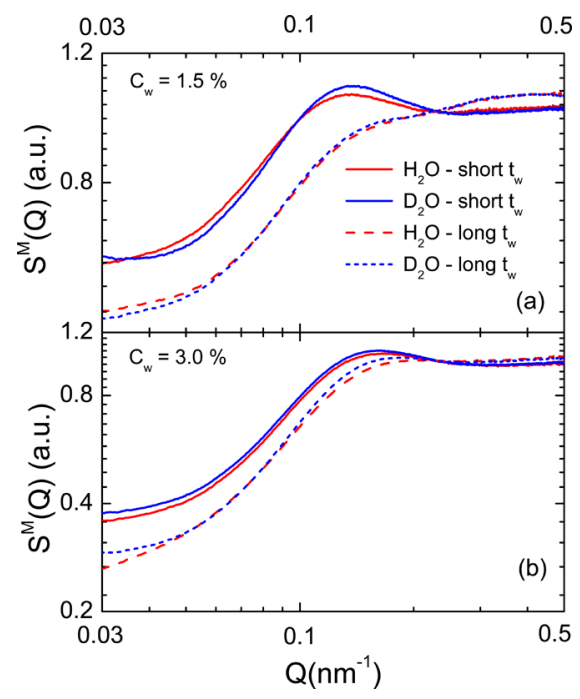

Figure 10. Measured static structure factor $S^{\mathrm{M}}(Q)$ as obtained by SAXS for samples at (a) low $C_{\mathrm{w}}=1.5 \%$ and (b) high $C_{\mathrm{w}}=3.0 \%$ Laponite concentration in $\mathrm{D}_{2} \mathrm{O}$ and $\mathrm{H}_{2} \mathrm{O}$ at short (full lines) and long (dashed lines) waiting times.

Finally, since $\mathrm{D}_{2} \mathrm{O}$ has the same chemical behavior of $\mathrm{H}_{2} \mathrm{O}$ and only differs in its mass and related properties, the structure should be preserved by $\mathrm{H} / \mathrm{D}$ isotopic substitution, and only dynamical properties should be affected, in agreement with our findings.

This study contributes to the general understanding of Laponite suspension behavior and is important for experiments in which isotopic substitution is required.

\section{AUTHOR INFORMATION}

\section{Corresponding Author}

*E-mail: flavio.marques@dfi.ufla.br.

\section{ORCID}

Flavio Augusto de Melo Marques: 0000-0002-6810-5955

\section{Notes}

The authors declare no competing financial interest.

\section{ACKNOWLEDGMENTS}

The authors thank ESRF for beamtime for this project. The staff at beamline ID02 is acknowledged for help during the experiments. The authors acknowledge support from the European Research Council (ERC Consolidator Grant 681597, MIMIC) and from MIUR-PRIN (2012J8X57P).

\section{REFERENCES}

(1) Pusey, P. N. Colloidal glasses. J. Phys.: Condens. Matter 2008, 20, $494202-494208$.

(2) Trappe, V.; Sandkühler, P. Colloidal gels - low-density disordered solid-like states. Curr. Opin. Colloid Interface Sci. 2004, 8, 494-500.

(3) Poon, W. C. K. Phase separation, aggregation and gelation in colloid polymer mixtures and related systems. Curr. Opin. Colloid Interface Sci. 1998, 3, 593-599.

(4) Zaccarelli, E.; Lu, P. J.; Ciulla, F.; Weitz, D. A.; Sciortino, F. Gelation as arrested phase separation in short-ranged attractive colloidpolymer mixtures. J. Phys.: Condens. Matter 2008, 20, 494242-494250.

(5) Sciortino, F.; Tartaglia, P. Glassy colloidal systems. Adv. Phys. 2005, 54, 471-524.

(6) Ruzicka, B.; Zaccarelli, E. A fresh look at the Laponite phase diagram. Soft Matter 2011, 7, 1268-1287.
(7) Michot, L. J.; Bihannic, I.; Maddi, S.; Funari, S. S.; Baravian, C.; Levitz, P.; Davidson, P. Liquid-crystalline aqueous clay suspensions. Proc. Natl. Acad. Sci. U. S. A. 2006, 103, 16101-16104.

(8) Shalkevich, A.; Stradner, A.; Bhat, S. K.; Muller, F.; Schurtenberger, P. Cluster, glass, and gel formation and viscoelastic phase separation in aqueous clay suspensions. Langmuir 2007, 23, $3570-3580$.

(9) Mourad, M. C. D.; Byelov, D. V.; Petukhov, A. V.; Matthijs de Winter, D. A.; Verkleij, A. J.; Lekkerkerker, H. N. W. Sol-gel transitions and liquid crystal phase transitions in concentrated aqueous suspensions of colloidal gibbsite platelets. J. Phys. Chem. B 2009, 113, 11604-11613.

(10) Pujala, R. K.; Joshi, N.; Bohidar, H. B. Spontaneous evolution of self-assembled phases from anisotropic colloidal dispersions. Colloid Polym. Sci. 2015, 293, 2883-2890.

(11) Ali, S.; Bandyopadhyay, R. Effect of electrolytes on the microstructure and yielding of aqueous dispersions of colloidal clay. Soft Matter 2016, 12, 414-435.

(12) BYK additives and instruments. www.byk.com (accessed: 201607-27).

(13) Glotzer, S. C.; Solomon, M. J. Anisotropy of building blocks and their assembly into complex structures. Nat. Mater. 2007, 6, 557-562.

(14) Mourchid, A.; Lecolier, E.; Van Damme, H.; Levitz, P. On viscolelastic, birefringent, and swelling properties of Laponite clay suspensions: Revisited phase diagram. Langmuir 1998, 14, 4718-4723.

(15) Tanaka, H.; Meunier, J.; Bonn, D. Nonergodic states of charged colloidal suspensions: Repulsive and attractive glasses and gels. Phys. Rev. E 2004, 69, 031404-031410.

(16) Mongondry, P.; Tassin, J. F.; Nicolai, T. Revised state diagram of Laponite dispersions. J. Colloid Interface Sci. 2005, 283, 397-405.

(17) Ruzicka, B.; Zulian, L.; Ruocco, G. Ergodic to non-ergodic transition in low concentration Laponite. Langmuir 2006, 22, 11061111.

(18) Cummins, H. Z. Liquid, glass, gel: The phases of colloidal Laponite. J. Non-Cryst. Solids 2007, 353, 3891.

(19) Ruzicka, B.; Zulian, L.; Ruocco, G. Ageing dynamics in Laponite dispersions at various salt concentrations. Philos. Mag. 2007, 87, 449458.

(20) Jabbari-Farouji, S.; Tanaka, H.; Wegdam, G. H.; Bonn, D. Multiple nonergodic disordered states in Laponite suspensions: A phase diagram. Phys. Rev. E 2008, 78, 061405-061415.

(21) Shahin, A.; Joshi, Y. M. Irreversible aging dynamics and generic phase behavior of aqueous suspensions of Laponite. Langmuir 2010, 26, 4219-4225.

(22) Mohanty, R. P.; Joshi, Y. M. Chemical stability phase diagram of aqueous Laponite dispersions. Appl. Clay Sci. 2016, 119, 243-248.

(23) Dijkstra, M.; Hansen, J. P.; Madden, P. A. Gelation of a clay colloid suspension. Phys. Rev. Lett. 1995, 75, 2236-2239.

(24) Kutter, S.; Hansen, J.; Sprik, M.; Boek, E. Structure and phase behavior of a model clay dispersion: A molecular-dynamics investigation. J. Chem. Phys. 2000, 112, 311-322.

(25) Trizac, E.; Bocquet, L.; Agra, R.; Weis, J.; Aubouy, M. Effective interactions and phase behaviour for a model clay suspension in an electrolyte. J. Phys.: Condens. Matter 2002, 14, 9339-9352.

(26) Odriozola, G.; Romero-Bastida, M.; de J. Guevara-Rodríguez, F. Brownian dynamics simulations of Laponite colloid suspensions. Phys. Rev. E 2004, 70, 021405-021419.

(27) Mossa, S.; de Michele, C.; Sciortino, F. Aging in a Laponite colloidal suspension: A Brownian dynamics simulation study. J. Chem. Phys. 2007, 126, 014905-014916.

(28) Jonsson, B.; Labbez, C.; Cabane, B. Interaction of nanometric clay platelets. Langmuir 2008, 24, 11406-11413.

(29) Delhorme, M.; Jönsson, B.; Labbez, C. Monte Carlo simulations of a clay inspired model suspension: The role of rim charge. Soft Matter 2012, 8, 9691-9704.

(30) Jabbari-Farouji, S.; Weis, J.-J.; Davidson, P.; Levitz, P.; Trizac, E. On phase behavior and dynamical signatures of charged colloidal platelets. Sci. Rep. 2013, 3, 3559-3565. 
(31) Ruzicka, B.; Zaccarelli, E.; Zulian, L.; Angelini, R.; Sztucki, M.; Moussaïd, A.; Narayanan, T.; Sciortino, F. Observation of empty liquids and equilibrium gels in a colloidal clay. Nat. Mater. 2011, 10, $56-60$.

(32) Bonn, D.; Tanaka, H.; Wegdam, G.; Kellay, H.; Meunier, J. Aging of a colloidal "Wigner" glass. Europhys. Lett. 1999, 45, 52-57.

(33) Ruzicka, B.; Zulian, L.; Zaccarelli, E.; Angelini, R.; Sztucki, M.; Moussaïd, A.; Ruocco, G. Competing interactions in arrested states of colloidal clays. Phys. Rev. Lett. 2010, 104, 085701-085705.

(34) Angelini, R.; Zaccarelli, E.; Marques, F.; Sztucki, M.; Fluerasu, A.; Ruocco, G.; Ruzicka, B. Glass-glass transition during aging of a colloidal clay. Nat. Commun. 2014, 5, 4049-4056.

(35) Martin, C.; Pignon, F.; Piau, J.-M.; Magnin, A.; Lindner, P.; Cabane, B. Dissociation of thixotropic clay gels. Phys. Rev. E: Stat. Phys., Plasmas, Fluids, Relat. Interdiscip. Top. 2002, 66, 021401021412.

(36) Bandyopadhyay, R.; Liang, D.; Yardimci, H.; Sessoms, D. A.; Borthwick, M. A.; Mochrie, S. G. J.; Harden, J. L.; Leheny, R. L. Evolution of particle-scale dynamics in an aging clay suspension. Phys. Rev. Lett. 2004, 93, 228302-228306.

(37) Schosseler, F.; Kaloun, S.; Skouri, M.; Munch, J. P. Diagram of the aging dynamics in laponite suspensions at low ionic strength. Phys. Rev. E 2006, 73, 021401-021410.

(38) Ruzicka, B.; Zulian, L.; Angelini, R.; Sztucki, M.; Moussaïd, A.; Ruocco, G. Arrested state of clay-water suspensions: Gel or glass? Phys. Rev. E 2008, 77, 020402-020406.

(39) Angelini, R.; Zulian, L.; Fluerasu, A.; Madsen, A.; Ruocco, G.; Ruzicka, B. Dichotomic aging behavior in a colloidal glass. Soft Matter 2013, 9, 10955-10959.

(40) Hansen, E. L.; Jabbari-Farouji, S.; Mauroy, H.; Plivelic, T. S.; Bonn, D.; Fossum, J. O. Orientational order in a glass of charged platelets with a concentration gradient. Soft Matter 2013, 9, 999910004.

(41) Marques, F.; Angelini, R.; Zaccarelli, E.; Farago, B.; Ruta, B.; Ruocco, G.; Ruzicka, B. Structural and microscopic relaxations in a colloidal glass. Soft Matter 2015, 11, 466-471.

(42) Nicolai, T.; Cocard, S. Dynamic light-scattering study of aggregating and gelling colloidal disks. J. Colloid Interface Sci. 2001, $244,51-57$.

(43) Bellour, M.; Knaebel, A.; Harden, J. L.; Lequeux, F.; Munch, J. P. Aging processes and scale dependance in soft glassy colloidal suspensions. Phys. Rev. E: Stat. Phys., Plasmas, Fluids, Relat. Interdiscip. Top. 2003, 67, 031405-031413.

(44) Ruzicka, B.; Zulian, L.; Ruocco, G. Routes to gelation in a clay suspension. Phys. Rev. Lett. 2004, 93, 258301-258305.

(45) Jabbari-Farouji, S.; Wegdam, G. H.; Bonn, D. Gels and glasses in a single system: Evidence for an intricate free-energy landscape of glassy materials. Phys. Rev. Lett. 2007, 99, 065701-065705.

(46) Pujala, R. K.; Bohidar, H. B. Ergodicity breaking and aging dynamics in Laponite-Montmorillonite mixed clay dispersions. Soft Matter 2012, 8, 6120-6128.

(47) Saha, D.; Joshi, Y. M.; Bandyopadhyayand, R. Investigation of the dynamical slowing down process in soft glassy colloidal suspensions: Comparisons with supercooled liquids. Soft Matter 2014, 10, 3292-3300.

(48) Saha, D.; Bandyopadhyay, R.; Joshi, Y. M. Dynamic light scattering study and DLVO analysis of physicochemical interactions in colloidal suspensions of charged disks. Langmuir 2015, 31, 30123020.

(49) Tudisca, V.; Ricci, M.; Angelini, R.; Ruzicka, B. Isotopic effect on the aging dynamics of a charged colloidal system. RSC Adv. 2012, 2, 11111-11116.

(50) Avery, R. G.; Ramsay, J. D. F. Colloidal properties of synthetic hectorite clay dispersions. J. Colloid Interface Sci. 1986, 109, 448-455.

(51) Grubel, G.; Zontone, F. Correlation spectroscopy with coherent X-rays. J. Alloys Compd. 2004, 362, 3-11.

(52) Lal, J.; Auvray, L. Interaction of polymer with clays. J. Appl. Crystallogr. 2000, 33, 673-676.
(53) Tawari, S. L.; Koch, D. L.; Cohen, C. Electrical double-layer effects on the Brownian diffusivity and aggregation rate of Laponite clay particles. J. Colloid Interface Sci. 2001, 240, 54-66.

(54) Kedenburg, S.; Vieweg, M.; Gissibl, T.; Giessen, H. Linear refractive index and absorption measurements of nonlinear optical liquids in the visible and near-infrared spectral region. Opt. Mater. Express 2012, 2, 1588-1611.

(55) Hardy, R. C.; Cottington, R. L. Viscosity of deuterium oxide and water from $5^{\circ}$ to $125^{\circ} \mathrm{C}$. J. Chem. Phys. 1949, 17, 509-510.

(56) Abou, B.; Bonn, D.; Meunier, J. Aging dynamics in a colloidal glass. Phys. Rev. E: Stat. Phys., Plasmas, Fluids, Relat. Interdiscip. Top. 2001, 64, 021510-021516.

(57) Kaloun, S.; Skouri, R.; Skouri, M.; Munch, J. P.; Schosseler, F. Successive exponential and full aging regimes evidenced by tracer diffusion in a colloidal glass. Phys. Rev. E 2005, 72, 011403-011408.

(58) Vidulich, G.; Evans, D.; Kay, R. The dielectric constant of water and heavy water between $0^{\circ}$ and $40^{\circ}$. J. Phys. Chem. 1967, 71, 656662.

(59) Nakamura, M.; Tamura, K.; Murakami, S. Isotope effects on thermodynamic properties: mixtures of $\mathrm{x}(\mathrm{D} 2 \mathrm{O}$ or $\mathrm{H} 2 \mathrm{O})+(1$ $\mathrm{x}) \mathrm{CH} 3 \mathrm{CN}$ at $298.15 \mathrm{~K}$. Thermochim. Acta 1995, 253, 127-136.

(60) Kell, G. S. Effects of isotopic composition, temperature, pressure, and dissolved gases on the density of liquid water. J. Phys. Chem. Ref. Data 1977, 6, 1109.

(61) Lide, D. R. Handbook of chemistry and physics, 84th ed.; CRC Press: United States, 2004.

(62) Jatav, S.; Joshi, Y. M. Chemical stability of Laponite in aqueous media. Appl. Clay Sci. 2014, 97-98, 72-77.

(63) Mourchid, A.; Levitz, P. Long-term gelation of laponite aqueous dispersions. Phys. Rev. E: Stat. Phys., Plasmas, Fluids, Relat. Interdiscip. Top. 1998, 57, R4887-R4890.

(64) Thompson, D. W.; Butterworth, J. The nature of Laponite and its aqueous dispersions. J. Colloid Interface Sci. 1992, 151, 236-243.

(65) Pek-Ing, A.; Yee-Kwong, L. Surface chemistry and rheology of Laponite dispersions - Zeta potential, yield stress, ageing, fractal dimension and pyrophosphate. Appl. Clay Sci. 2015, 107, 36-45. 